\title{
Performance Analysis of CSI Based PV system During LL and TPG faults
}

\author{
N.Umamaheswari ${ }^{1}$, P.Srinivas Raju ${ }^{2}$, K.Sravanthi ${ }^{3}$, K.Kalyan Kumar ${ }^{4}$ \\ 1,2,3,4 (EEE Department, Vardahaman College of Engineering/JNTU,INDIA)
}

\begin{abstract}
To enlarge the use of grid-connected PV systems, the cost, performance, and life expectancy of the power electronic interface needs to be improved. The current-source inverter (CSI) offers advantages over VSI in terms of inherent boosting and short-circuit protection capabilities, direct output current controllability, and ac-side simpler filter structure. Research on CSI-based DG is still in its infancy. This paper focuses on transient performances of a PV system based on CSI during the rigorous LL and TPG (Three-phase-to-ground) faults. It also performs a comparative analysis of CSI-based PV systems for severe LL and TPG (Three-phase- toground) faults under transient conditions. The control structure consists of two current control loops. An MPPT provides the reference for the outer dc-side current control loop. The inner current control loop is designed to control the current that is injected into the grid. Using a case study of grid-side faults i.e., LL, TPG, the designed controller is able to fulfill all the requirements of a PV system grid interface besides limiting the dcside current, irrespective of the severity of the fault, unlike a VSI-based PV system. The fault studies included line-to-line and three-phase-to-ground faults.The case study of this paper is presented by using a Mat lab / Simulink environment, the respective results also shows the differences between the behaviour of a system at the time of encountering faults.
\end{abstract}

Keywords - Current source inverter (CSI), Controller, Faults, Grid, PV System, transient conditions.

\section{Introduction}

An attractive feature of $\mathrm{PV}$ systems is that they produce electric power without harming the environment, by directly transforming a free unlimited source of energy, solar radiation, into electricity. This fact along with the continuing decrease in PV arrays cost and the increase in their efficiency has resulted in the use of PV generation systems. In the past, PV sources were commonly used in isolated and stand-alone applications. Nowadays, the trend is to connect the PV systems to the public grid, selling the generated power with advantageous price ratings fixed by governmental policies. The present practice in PV inverter mainly depends on voltage-source inverter (VSI) topology which normally requires another stage of power-electronic conversion for stepping up the voltage of the PV modules for a large-scale PV inverter. The use of PV system in power systems can increase by reducing the cost and improving the robustness and performance of powerelectronic grid interface. Single-and two-stage grid-connected systems are commonly used topologies in singleand three-phase PV applications [1], [2]. In single-stage, inverter control is complicated and two-stage technique suffers from reduced efficiency, higher cost, and larger size. Due to the Drawbacks of Single-and two-stage grid-connected systems, conventional voltage source inverter (VSI) is the most commonly used interface unit in grid-connected PV system technology [3]. The properties of the VSI increase the necessity of using a bulky transformer or higher dc voltage. Also an electrolytic capacitor, which shows a critical point of failure, is also needed. Here the advantages are achieved at the cost of a more complex PV system in addition with a bulky transformer and an unreliable electrolytic capacitor.

The current-source inverter (CSI) has become a preferred topology for interfacing a PV system to the ac power grid for the following reasons [6]. 1) CSI provides a continuous dc-side current, which is a useful feature for PV modules. 2) The energy storing element of CSI has a longer lifetime than VSI. 3) the CSI voltage boosting capability allows a low-voltage PV array to be grid interface without the need of a trans-former or an additional boost stage.4) With the development of reverse-blocking (RB) IGBT switches, the series diodes will be eliminated, resulting in a significant reduction in the cost and conduction losses. 5) The progress in superconductor technology has led to the development of superconducting magnetic energy storage (SMES) systems, can reduce the losses in the energy storage element of the CSI.

There are many applications of CSI topology in PV systems, which have come up with certain advantages and disadvantages. The performance of a single phase, grid connected CSI is detailed in [4].In [4] CSI is combined with the boost converter which acts as a wave shaper. However, the dynamic performance of the PV inverter in response to solar isolation level and behavior of PV system under faulty conditions is not addressed. The performance of CSI used in three phase transformer less grid-connected PV system is evaluated with maximum power point tracking(MPPT) system and PWM control scheme in [5].one major drawback of the control method in [5] is that it does not allow the PV inverter to operate in standalone mode. 
This paper presents transient performance of a PV system based on CSI during the rigorous LL and TPG (Three- phase- to-ground) faults. Also comparative analysis of CSI-based PV systems for severe LL and TPG (Three-phase- to-ground) faults under transient conditions is studied.

\section{Pv System Description}

Photovoltaic's is the field of technology and research related to the devices which directly convert sunlight into electricity using semiconductors that exhibit the photovoltaic effect. Photovoltaic effect involves the creation of voltage in a material upon exposure to electromagnetic radiation. The solar cell is the elementary building block of the photovoltaic technology. Solar cells are made of semiconductor materials, such as silicon.

\subsection{Grid Connected PV systems}

Fig. 1 shows the single-line diagram of the three phase, single-stage, grid connected PV system using CSI [6].A PV array is a parallel combination of $n_{p}$ PV modules. A single PV module consists of a number of PV cells in series and a PV cell is modeled as a current source shunted with a diode. The ripples in dc side current is filtered and controlled by dc side inductor. The ac side inverter is interfaced with the primary side of transformer through capacitive filter which consists of three $\mathrm{Y}$-connected capacitors $\mathrm{c}_{\mathrm{f}}$. The function of $\mathrm{c}_{\mathrm{f}}$ is to absorb switching harmonics and produce smooth sinusoidal current at the grid interface. When there is fault on the secondary side of the transformer, Breaker is used to protect the PV system by isolating it. The primary side of the transformer is connected in delta whereas the secondary side is connected in star with a neutral point. In Fig. $1 \mathrm{R}_{\mathrm{g}}$ and $\mathrm{L}_{\mathrm{g}}$ are resistance and inductance of the distributed line. Similarly $\mathrm{P}_{\mathrm{s}}$ and $\mathrm{Q}_{\mathrm{s}}$ represent the active and reactive powers supplied by the PV system to the distribution system.

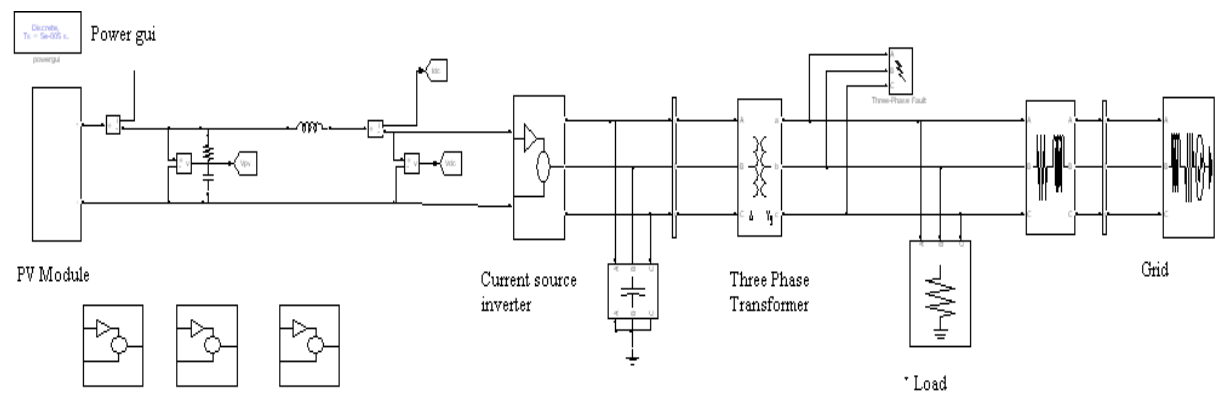

Fig. 1 Simulink model for CSI Based Grid connected PV system

\subsection{PV Array Characteristics}

The P-I characteristic is described by the equations derived in [6], thus we obtain the power equation as

$$
\begin{aligned}
P_{\mathrm{pv}}=0.01 n_{p}\left[i_{\mathrm{scr}}+K_{\vartheta}\left(T_{c}-T_{\mathrm{ref}}\right)\right] S v_{\mathrm{pv}} \\
\quad-n_{p} i_{\mathrm{rs}} v_{\mathrm{pv}}\left[\exp \left(\frac{q}{k T_{c} A} \frac{v_{\mathrm{pv}}}{n_{s}}\right)-1\right] .
\end{aligned}
$$

from the power equation shown, it is evident that the power supplied by the PV array is a function of insulation level at any given temperature.

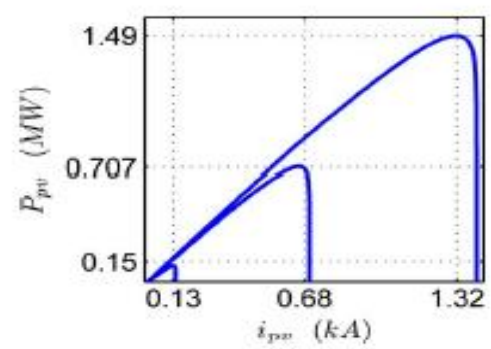

Fig.2. P-I characteristics of PV array for different isolation levels

Since the inverter used in PV system is of current-source type, the power-versus-current characteristic of the PV array is observed. Fig. 2[6] shows the power-current characteristic of the PV array for different insulation levels. 


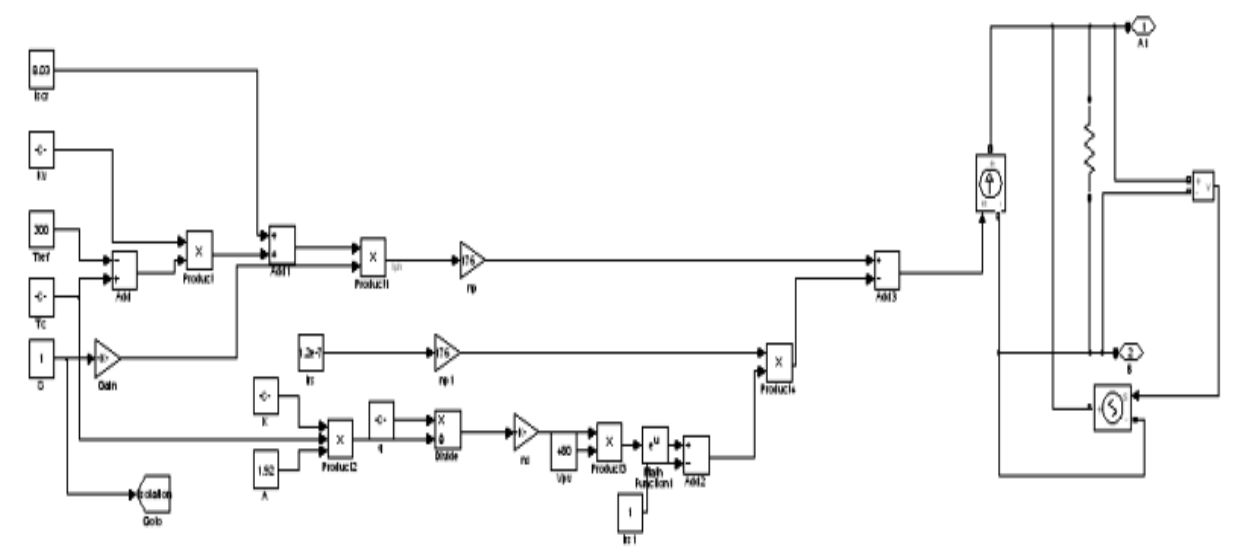

Fig. 3 Simulink model for PV Array

\subsection{Operation of controller}

\section{CSI-Based PV System Controller}

A grid-connected CSI-based PV system controller is designed to control the dc and ac side currents to make certain: 1) The real power fed to the grid is equal to the maximum power that can be extracted from the PV panel under all conditions; 2) a high-quality sinusoidal current is fed to grid; and 3) At the interface with grid reactive power assumes the desired value. From Fig. 1, phase-locked loop (PLL) [7] is used to synchronize the pulsewidth modulation (PWM) and control of the CSI to the grid voltage also two PI controllers are used to process the errors between the reference commands, $i_{\text {sdref }}$ and $i_{\text {sqref }}$ and the $\mathrm{d}$-axis and q-axis components of the ac-side current and generate the modulating signals, $\mathrm{m}_{\mathrm{d}}$ and $\mathrm{m}_{\mathrm{q}}$.

\section{2 phase locked Loop}

As mentioned in [6] dq frame which is rotating at angular speed $\omega$, ac variables are projected. The ac variables are sinusoidal functions of the grid frequency $\omega_{0}$ in steady state,. If the $\mathrm{dq}$-frame angular speed is adjusted to the grid frequency, the changed quantities in steady state become time invariant which makes controller design simpler. This is achieved by means of a PLL [7] whose block diagram is given in [6]. As shown in [6], the input to the PLL block is sinusoidally varying voltage and the output is the angle for abc-to-dq and dq -to- abc $\mathrm{v}_{\mathrm{s}}$ transformations, $\delta$. The active power is independent of the voltage $\mathrm{v}_{\mathrm{sq}}$ and reactive power is controlled by $i_{\mathrm{sq}}$.

\subsection{Design of Inner Current Control Loop}

Equations in [6] show that active and reactive powers delivered by CSI can be adjusted by controlling $i_{s d}$ and $i_{s q}$. The block diagram [6] of the CSI ac-side current controller consists of $K_{d}(S)$ and $K_{q}(S)$ which are expressed as

$$
k_{d}(s)=k_{q}(s)=k_{p}+\frac{k_{i}}{s}
$$

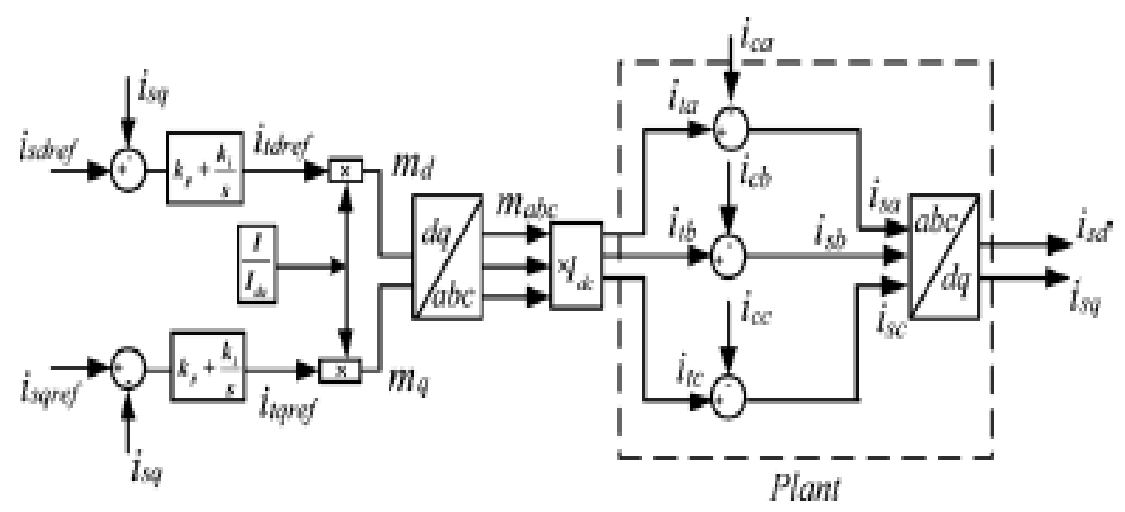

Fig.4. Block diagram for ac-side current control system of CSI 
where $K_{p}$ and $K_{i}$ are the proportional and integral gains, $M_{d}$ and $M_{q}$ are Control signals, $i_{\text {tdref }}$ and $i_{\text {tqref }}$ are current references derived from the outputs of the compensators $\mathrm{K}_{\mathrm{d}}(\mathrm{S})$ and $\mathrm{K}_{\mathrm{q}}(\mathrm{S})$, respectively. The Transfer function for the closed-loop control system of $i_{\text {sd }}$ shown in Fig. 3

$$
T(s)=\frac{i_{s d}}{i_{s d \text { ref }}}=\frac{k_{p}+\frac{K_{i}}{s}}{k_{p}+\frac{k_{i}}{s}+1}=\frac{s \frac{k_{p}}{k_{p}+1}+\frac{k_{i}}{k_{p}+1}}{s+\frac{k_{i}}{k_{p}+1}} .
$$

As the value of $k_{p}$ increases, the pole of the transfer function $T(s)$ in (2) reaches the origin of S-plane, which is not desirable. Therefore, $\mathrm{k}_{\mathrm{p}}$ should be chosen small to reproduce the transient behavior of a first-order system, $\mathrm{k}_{\mathrm{i}}$ as inverse of time-constant, $\mathrm{T}_{\mathrm{i}}$ is chosen in the range of $0.5-5 \mathrm{~ms}$ to get a fast and accurate response. Thus, $\mathrm{k}_{\mathrm{p}}$ and $\mathrm{k}_{\mathrm{i}}$ are written as

$$
k_{p} \approx 0 \quad \text { and } \quad k_{i}=\frac{1}{\tau_{i}} \text {. }
$$

Substituting these values of and in (2), the transfer function $\mathrm{T}(\mathrm{s})$ becomes

$$
T(s)=\frac{i_{s d}}{i_{s d r e f}}=\frac{\frac{1}{\tau_{i}}}{s+\frac{1}{\tau_{i}}}=\frac{1}{\tau_{i} s+1} .
$$

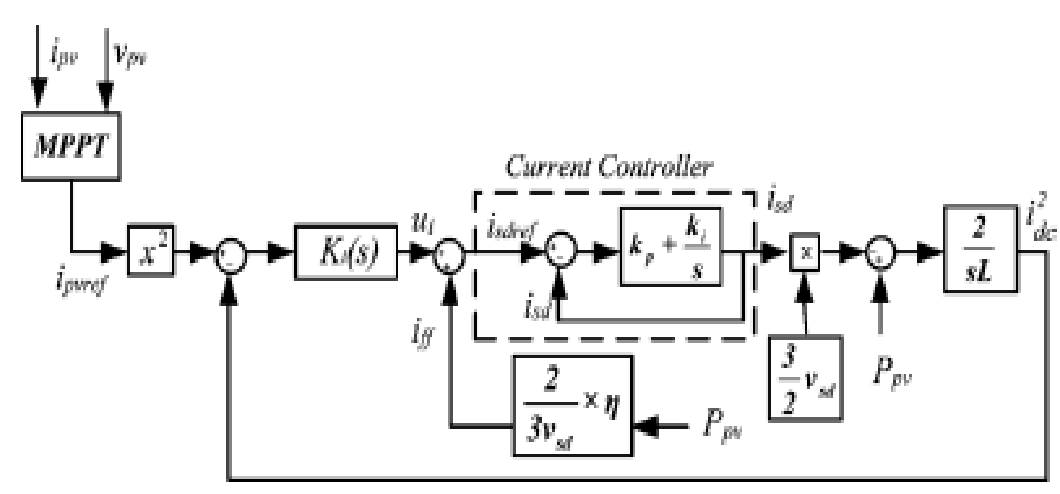

Fig.5. Closed-loop control structure of the dc-side current.

\subsection{Design of Outer Current Control Loop}

From the mathematical model [6] of controller we obtain the power equation

$$
\frac{1}{2} L_{\mathrm{dc}} \frac{d i_{\mathrm{dc}}^{2}}{d t}=P_{\mathrm{pv}}-\frac{3}{2}\left(v_{s d} i_{s d}+v_{s q} i_{s q}\right) .
$$

After substituting $\mathrm{V}_{\mathrm{sq}}=0$ in equation (2), represents a system with $\mathrm{i}_{\mathrm{sd}}$ as the input, $i_{\mathrm{dc}}^{2}$ as output and $\mathrm{v}_{\mathrm{sd}}$ the disturbance input. In Current controller PI compensator, if time constant is selected properly, $i_{s d}$ can be approximated to $i_{\text {sdref. }}$. Therefore, (3) can be rewritten as

$$
\frac{1}{2} L_{\mathrm{dc}} \frac{d i_{\mathrm{dc}}^{2}}{d t} \approx P_{\mathrm{pv}}-\frac{3}{2} v_{s d} i_{s d \mathrm{ref}} .
$$

The dc-link current controller designed from (4) is illustrated in Fig. 4. From (4) Ppv is product of $v_{p v}$ and $i_{d c}$ which makes the system nonlinear. To remove the impact of nonlinearity, $i_{\text {sdref }}$ can be derived in the following

$$
i_{s d \text { ref }}=u_{i}+\eta \underbrace{\left(\frac{P_{\mathrm{pv}}}{\frac{3}{2} v_{s d}}\right)}_{i_{\mathrm{ff}}}
$$


Where $u_{i}$ is a new control input and $i_{\text {ff }}$ is a feed-forward signal that can be enabled or disabled depending on the value of binary multiplier assumes unity or zero. Substituting $i_{\text {sdref }}$ in (4), the following equation is obtained.

$$
\frac{L_{\mathrm{dc}}}{2} \frac{d i_{\mathrm{dc}}^{2}}{d t} \approx(1-\eta) P_{\mathrm{pv}}-\frac{3}{2} v_{s d} u_{i} .
$$

From (6) if $\eta=1$ indicates that the impact of the PV array nonlinearity on the dc-side current control is eliminated and control unit acts as an integrator.

\section{Comparative Performance Assessment Of CSI based Grid Connected PV system under \\ LL and TPG Faults} 4.1 Fault Analysis

Some of the major Electrical faults are phase faults include phase to phase faults and phase to ground faults and three phase faults. Faults results in the overloads is due to passing the current through the conductor which is above the permissible value and faults due to real power insufficiency occurs due to mismatch in the power generated and consumed and results in the frequency deviation and collapse of grid.Electrical Phase faults are characterised as: Phase to Ground Fault, Phase to Phase Fault, Phase - Phase to Ground Fault, Three Phase Fault, Three Phase to Ground Fault. An Unsymmetrical or unbalanced fault does not affect each of the three phases equally. Common types of asymmetric faults, and their causes:

- line-to-line - A short circuit between lines, caused by ionization of air, or when lines come into physical contact.

- line-to-ground - A short circuit between one line and ground, very often caused by physical contact.

- double line-to-ground - two lines come into contact with the ground (and each other).

TPG faults are called symmetrical faults. Since the three phases are equally affected, the system remains balanced. That is why, this fault is called a symmetrical or a balanced fault and the fault analysis is done on per phase basis.

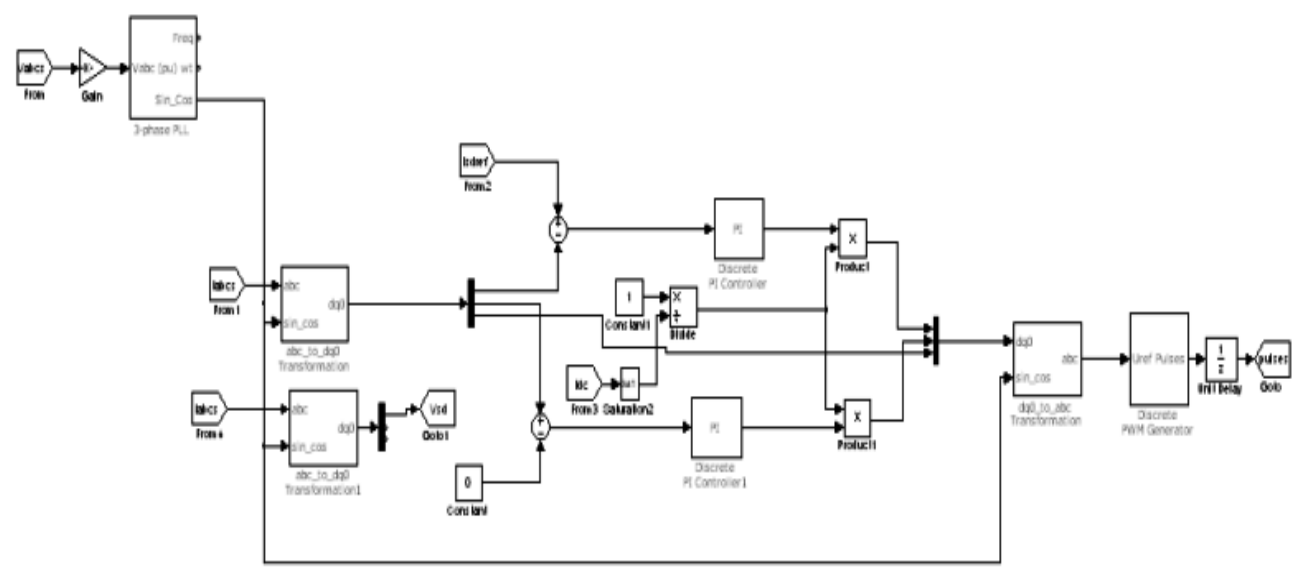

Fig. 5 Simulink model for Three-phase-to-ground-fault of Grid connected PV system

Fault analysis in solar photovoltaic (PV) arrays is a primary task to increase system reliability, efficiency, and safety. Without proper protection, faults in PV systems may damage PV modules and cables, as also lead to dc arcing hazards and even fire risks. There are many fire hazards taken place in power stations due to these faults. In addition to fire hazards, faults in PV arrays result in a large amount of energy loss. In order to overcome these problems, discovered the following statements [8]-[11]:

1) There still exist some unknown "blind spots" in PV protection schemes that need special consideration and 2) PV arrays are unique from traditional power sources and have unique fault scenarios. Depending on location, fault analysis approaches for PV system is categorized into three parts: faults on PV arrays [12]-[13], failure within power conditioning unit [14]-[15], and abnormality on utility grid [16]-[18]. 


\subsection{Fault Conditions}

Due to fault on the grid side of inverter, oscillations of voltage and current occur on dc side of inverter [12]. Oscillations in the dc side current are not desirable as the inverter requires continuous input dc current. In CSI based PV system dc side current is regulated and restricted which results in that the current in the ac side inverter may not show a quick raise under fault. In practical when the fault occurs on the grid side and the breaker opens, the anti-islanding scheme must act to protect the inverter. But here the anti-islanding scheme is disabled in order to show the impact of Change in ac-side voltage level on the performance of PV system.

At time $\mathrm{t}=1.5 \mathrm{~s}$, an LL fault is applied on phase-a of secondary side of the transformer. Due to the fault, the voltage drops to zero, as shown in Fig. 6(a). When fault is applied on the ac-side it resulted in oscillations in dcside current of the CSI, as shown in Fig. 6(b). However, as soon as the fault is cleared oscillations are damped and the dc-side current controller tracks the reference current in less than $20 \mathrm{~ms}$. Due to this disturbance, the ac side current of the CSI undergoes over modulation, as shown in Fig. 6(c). Due to over modulation lower order harmonics results, which makes the current flowing into the grid non-sinusoidal is as shown in Fig. 6(d). This case study shows a CSI that has built in over-current protection to restrict the current on both dc and ac sides. Similar responses are observed for TPG faults, as shown in Figs. 6(e)-(h).

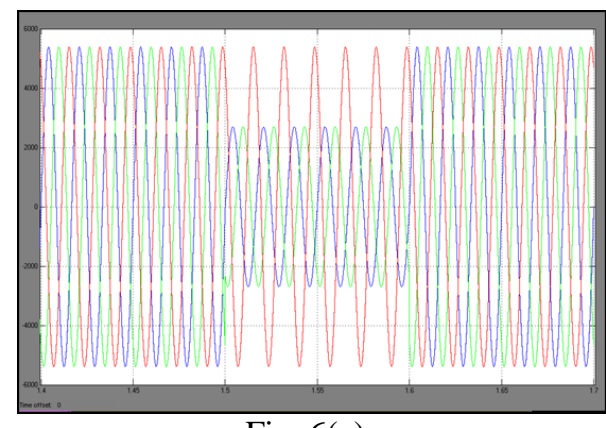

Fig. 6(a).

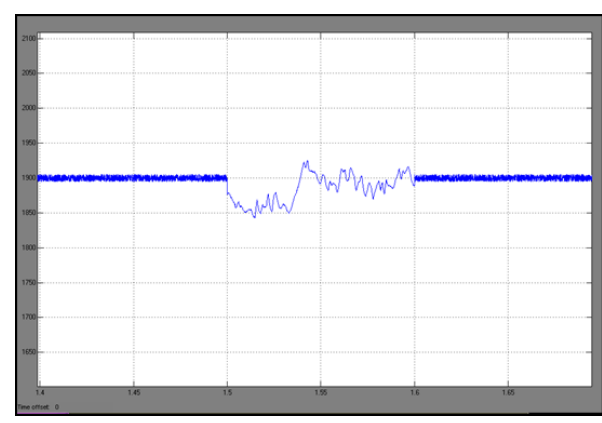

Fig. 6(b).

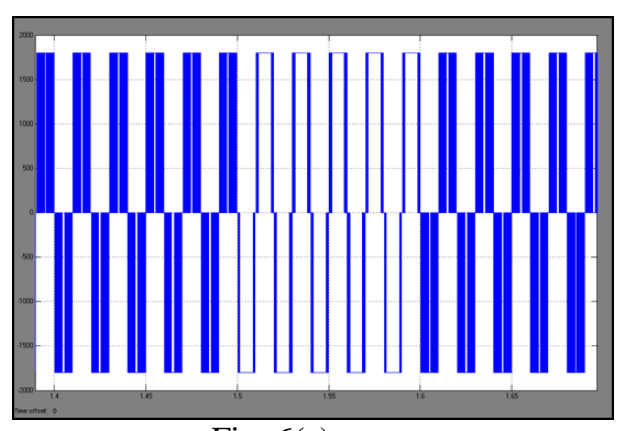

Fig. 6(c).

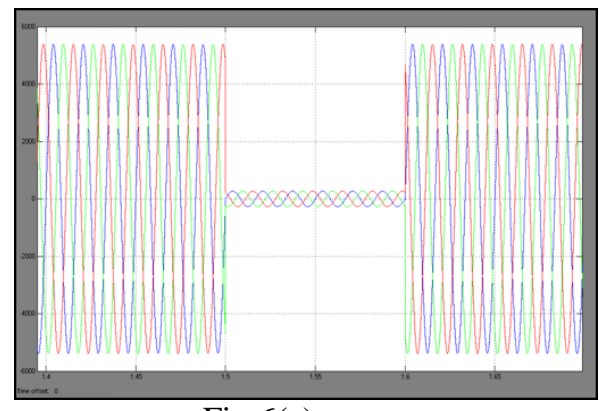

Fig.6(e).

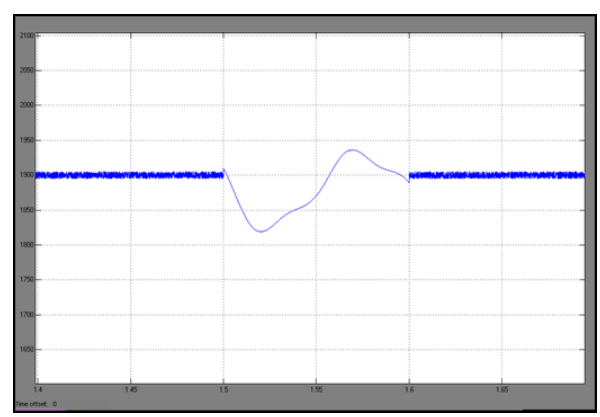

Fig. 6(f).

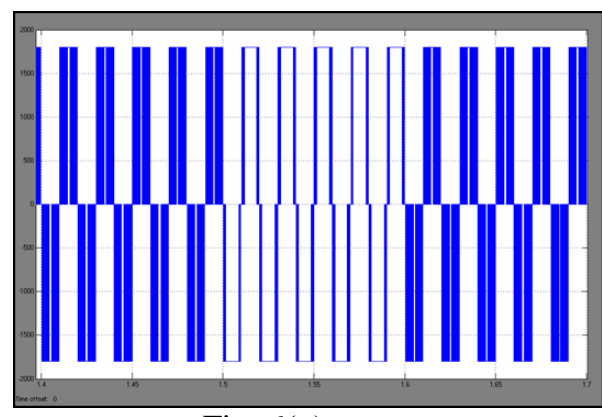

Fig. 6(g). 


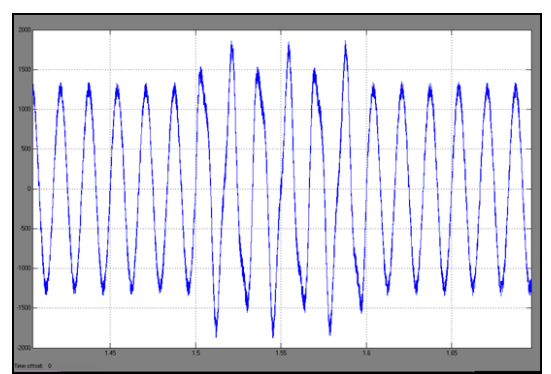

Fig. 6(d).

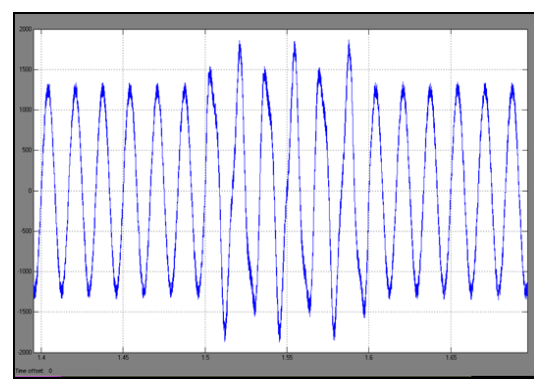

Fig. 6(h).

Fig. 6. Simulink Results for CSI-based PV system performance during LL and TPG faults

\section{CONCLUSION}

The number of PV installations is increasing at more than $20 \%$ a year. Nearly all PV systems will soon be required to have a ground-fault protective device that will minimize the possibility of fires starting from ground faults in PV arrays. Efforts are continuing to enhance the safety of PV systems for the general public through revisions and additions to the National Electrical Code and UL Standards. The goal is to have safe, reliable, and cost-effective PV systems. The green future must be a safe future.This paper presents the single stage, three phase grid connected PV system based on CSI and compared the output signals $v_{\mathrm{abc}}, \mathrm{i}_{\mathrm{dc}}, \mathrm{i}_{\mathrm{ta}}, \mathrm{i}_{\mathrm{sa}}$ in each one of the faults. The result shows that the interruption due to three phase to ground fault is noticeably more than the line to line fault. The proposed model provides a useful tool to study the changes of active and reactive powers and the output current during the mentioned faults. Through simulation studies, it was shown that the CSI-based PV system, with the designed controller,was able to fulfill all the requirements of a PV system grid interface beside limiting the dc-side current, irrespective of the severity of the fault, unlike a VSIbased PV system. Further this work could be extended using Fuzzy Logic which reduces the ripples in dc side input current of CSI.

\section{References}

[1] Y. Bo, L.Wuhua, Z. Yi, and H. Xiangning, "Design and analysis of a grid connected photovoltaic power system," IEEE Trans. Power Electron.,vol. 25, no. 4, pp. 992-1000, Apr. 2010.

[2] W. Tsai-Fu, C. Chih-Hao, L. Li-Chiun, and K. Chia-Ling, "Power losscomparison of single- and two-stage grid-connected photovoltaic systems,"IEEE Trans. Energy Convers., vol. 26, no. 2, pp. 707-715, Jun.2011.

[3] G. Petrone, G. Spagnuolo, and M. Vitelli, "A multivariable perturb-and-observe maximum power point tracking technique applied to a single-stage photovoltaic inverter,” IEEE Trans. Ind. Electron., vol. 58,no. 1, pp. 76-84, Jan. 2011.

[4] Y. Neba, "A simple method for suppression of resonance oscillation inpwm current source converter," IEEE Trans. Power Electron., vol. 20,no. 1, pp. 132-139, Jan. 2005.

[5] G. Ertasgin, D. M. Whaley, and N. Ertugrul, "Implementation and performance evaluation of a low-cost current-source gridconnected inverter for pv application," in Proc. Int. Conf. Sustainable Energy Technologies, 2008, pp. 939-944.

[6] P. Paramita Das, Mehrdad Kazerani, "Dynamic Modeling and Performance Analysis of a Grid-Connected Current-Source InverterBased Photovoltaic System" in Proc IEEE Trans.sustainable energy, vol. 2, no. 4, october 2011.

[7] S. K. Chung, "A phase tracking system for three phase utility interface inverters," IEEE Trans. Power Electron., vol. 15, no. 3, pp. 431-438, 2000.

[8] Y. Zhao, B. Lehman, J. F. de Palma, J. Mosesian, and R. Lyons, "Fault evolution in photovoltaic array during night-to-day transition," in Proc IEEE COMPEL, 2010, pp. 1-6.

[9] Y. Zhao, B. Lehman, J. F. de Palma, J. Mosesian, and R. Lyons, "Fault analysis in solar PV arrays under: Low irradiance conditions and reverse connections," in Proc. 37th IEEE PVSC, Seattle, WA, 2011, pp. 002000-002005.

[10] Y. Zhao, B. Lehman, J. F. de Palma, J. Mosesian, and R. Lyons, "Challenges of overcurrent protection devices in photovoltaic arrays brought by maximum power point tracker," in Proc. 37th IEEE PVSC, Seattle, WA 2011, pp. 002472-002477.

[11] Y. Zhao, B. Lehman, J. F. de Palma, J. Mosesian, and R. Lyons, "Challenges to overcurrent protection devices under line-line faults in solar photovoltaic arrays," in Proc. IEEE ECCE, Phoenix, AZ, 2011pp. 20-27.

[12] S. K. Firth, K. J. Lomas, and S. J. Rees, "A simple model of PV system performance and its use in fault detection," Solar Energy, vol. 84, no. 4, pp. 624-635, Jan. 2010.

[13] Y. Zhao, B. Lehman, J. F. de Palma, J. Mosesian, and R. Lyons, "Fault evolution in photovoltaic array during night-to-day transition," in Proc. IEEE COMPEL, 2010, pp. 1-6.

[14] F. Chan and H. Calleja, "Reliability estimation of three single-phase topologies in grid-connected PV systems," IEEE Trans. Ind. Electron., vol. 58, no. 7, pp. 2683-2689, Jul. 2011.

[15] J. Young-Hyok, D.-Y. Jung, J.-G. Kim, J.-H. Kim, T.-W. Lee, and C.-Y. Won, “A real maximum power point tracking method for mismatching compensation in PV array under partially shaded conditions," IEEE Trans. Power Electron., vol. 26, no. 4, pp. 10011009, Apr. 2011

[16] E. J. Estébanez, V. M. Moreno, A. Pigazo,M. Liserre, and A. Dell'Aquila, "Performance evaluation of active islanding-detection algorithms in distributed-generation photovoltaic systems: Two inverters case," IEEE Trans. Ind. Electron., vol. 58, no. 4, pp. 11851193, Apr. 2011.

[17] G. Petrone, G. Spagnuolo, R. Teodorescu, M. Veerachary, and M. Vitelli,“Reliability issues in photovoltaic power processing systems," IEEE Trans. Ind. Electron., vol. 55, no. 7, pp. 2569-2580, Jul. 2008.

[18] Y. Byung-Gyu, M. Matsui, and Y. Gwon-Jong, "A correlation-based islanding-detection method using current-magnitude disturbance for PV system,” IEEE Trans. Ind. Electron., vol. 58, no. 7, pp. 2935-2943, Jul. 2011. 